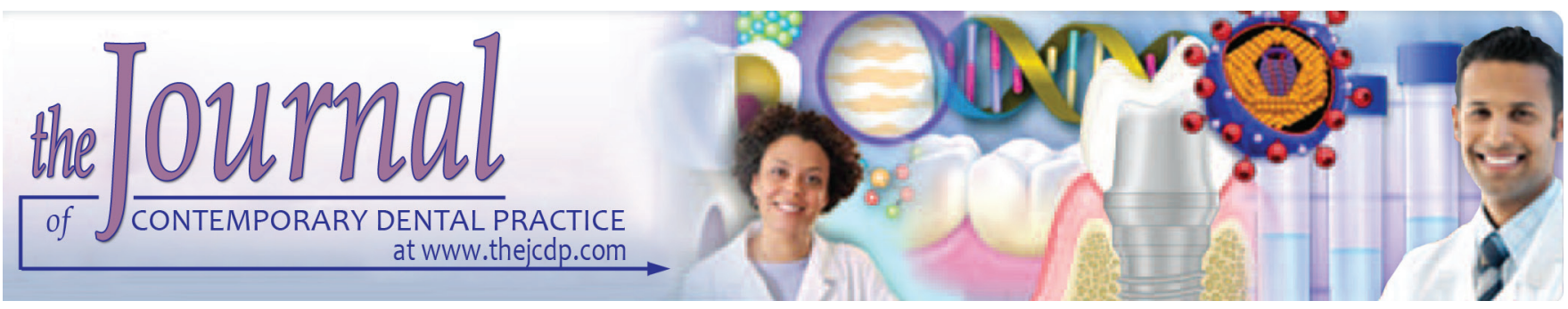

\title{
Structural and Morphological Evaluation of Presintered Zirconia following Different Surface Treatments
}

\author{
${ }^{1}$ Hasan Skienhe, ${ }^{2}$ Roland Habchi, ${ }^{3}$ Hani F Ounsi, ${ }^{4}$ Marco Ferrari, ${ }^{5}$ Ziad Salameh
}

\begin{abstract}
Aim: The aim of this study was to evaluate the effect of different surface treatments on roughness, grain size, and phase transformation of presintered zirconia.
\end{abstract}

Materials and methods: Surface treatments included airborne particle abrasion (APA) before and after sintering with different particles shape, size, and pressure $\left(50 \mu \mathrm{m} \mathrm{Al}_{2} \mathrm{O}_{3}, 50 \mu \mathrm{m}\right.$ glass beads, and ceramic powder). Thirty-five square-shaped presintered yttrium-stabilized tetragonal zirconia polycrystal (Y-TZP) ceramic slabs (Zenostar ZR bridge, Wieland) were prepared (4 mm height $\times 10 \mathrm{~mm}$ width $\times 10 \mathrm{~mm}$ length) and polished with silicon carbide grit papers $\# 800,1000,1200,1500$, and 2000 to ensure identical initial roughness. Specimens were divided into five groups according to surface treatment: group I (control): no surface treatment; group II: APA $50 \mu \mathrm{m} \mathrm{Al}_{2} \mathrm{O}_{3}$ after sintering; group III: APA $50 \mu \mathrm{m} \mathrm{Al}_{2} \mathrm{O}_{3}$ particles before sintering; group IV: APA $50 \mu \mathrm{m}$ glass bead particles before sintering; and group $\mathrm{V}$ : APA ceramic powder before sintering. Specimens were analyzed using scanning electron microscopy (SEM), atomic force microscopy (AFM), X-ray diffraction (XRD) analyses, and tested for shear bond strength (SBS). Data were statistically analyzed using one-way analysis of variance (ANOVA) followed by post hoc tests for multiple comparisons Tukey's test $(\alpha \geq 0.05)$.

${ }^{1}$ Doctoral School of Science and Technology, Lebanese
University, Beirut, Lebanon
${ }^{2}$ Department of Nanosciences and Nanotechnology. Campus
Pierre Gemayel, Fanar, Lebanese University

${ }^{3}$ Department of Restorative Dentistry and Endodontics, Faculty of Dental Medicine Lebanese University, Beirut, Lebanon Department of Restorative Dentistry and Endodontics, Faculty of Dental Medicine, University of Siena, Siena, Italy

${ }^{4}$ Department of Prosthodontics and Dental Materials, School of Dental Medicine, University of Siena, Siena, Italy

${ }^{5}$ Department of Research, Faculty of Dental Medicine, Lebanese University, Beirut, Lebanon

Corresponding Author: Hasan Skienhe, Doctoral School of Science and Technology, Lebanese University, Beirut, Lebanon Phone: +9613600991, e-mail: hasanskienhe123@gmail.com
Results: Air abrasion before sintering significantly increased the surface roughness when compared with groups I and III. The highest tetragonal to monoclinic ( $\mathrm{t}-\mathrm{m})$ phase transformation $(0.07 \%)$ was observed in group III, and a reverse transformation was observed in presintered groups $(0.01 \%)$. Regarding bond strength, there was a significant difference between APA procedures pre- and postsintering.

Conclusion: Air abrasion before sintering is a valuable method for increasing surface roughness and SBS. The abrasive particles' size and type used before sintering had a little effect on phase transformation.

Clinical significance: Air abrasion before sintering could be supposed to be an alternative surface treatment method to air abrasion after sintering.

Keywords: Air abrasion, Bond strength, Grain size, Presintered zirconia, Surface roughness.

How to cite this article: Skienhe $\mathrm{H}$, Habchi R, Ounsi HF, Ferrari M, Salameh Z. Structural and Morphological Evaluation of Presintered Zirconia following Different Surface Treatments. J Contemp Dent Pract 2018;19(2):156-165.

Source of support: This work was supported by the Doctorate School for Sciences and Technology Lebanese University, Beirut, Lebanon.

Conflict of interest: None

\section{INTRODUCTION}

Advances in computer-aided design/computer-aided machining technologies have facilitated the manufacture of zirconia prostheses. ${ }^{1}$ However, a durable bond strength between zirconia-based materials and resin cement has proven to be difficult. ${ }^{2}$ This is related to the glass-free composition structure characterizing zirconia as an acid-resistant material. ${ }^{3}$ Clinically, the most frequently reported complications of zirconia-based ceramics are chipping of veneering porcelains and loss of retention. ${ }^{4,5}$

A strong and durable bond to zirconia ceramic can be achieved either by mechanical and / or chemical bonding of resin cement to zirconia surface. ${ }^{6,7}$ Many surface 
treatment methods have been introduced to improve the adhesion to zirconia ceramics. Air-particle abrasion was reported to enhance significantly the adhesion between resin cement and zirconia ceramics. ${ }^{8}$ This is achieved through increasing surface roughness and micromechanical interlocking. ${ }^{9}$ Air abrasion creates, however, surface flaws, which may act as stress raisers and crack initiation sites. It may also result in a t-m phase transformation. ${ }^{10,11}$

Other surface treatment methods include tribochemical silica coating, ${ }^{12}$ selective infiltration etching, ${ }^{13}$ hot chemical etching, ${ }^{14}$ laser treatment, ${ }^{15,16}$ and nanostructured alumina coating. ${ }^{17}$ These have enhanced bond strengths to zirconia, but these methods often require special equipment. Moreover, there is no consensus regarding the most appropriate or reliable method with which to bond zirconia restorations. ${ }^{18}$

Recent studies reported that tribochemical silica coating induces $\mathrm{t}-\mathrm{m}$ phase transformation, ${ }^{19}$ and that bond strength of tribochemical silica-coated surfaces decreased after forceful water stream, ultrasonic cleaning, and water-mist spraying. ${ }^{20-22}$

As for chemical bonding, many studies reported that using primers and resin cement based on 10-methacryloyloxydecyl dihydrogen phosphate (MDP) monomer increased bond strength. ${ }^{23,24}$ They are considered as materials of choice for cementation of indirect alumina and zirconia restorations, since MDP monomer bonded directly to metal oxides and the phosphoric-acid groups of MDP can react with the oxide layer on the zirconia surface. ${ }^{25,26}$

It was also shown in previous studies that the creation of a micro-retentive surface is an important factor for achieving strong and durable adhesion, and promotes as well the chemical reaction with MDP monomer. ${ }^{27,28}$ Furthermore, the combination of air abrasion and resin cement containing MDP monomer increases the bond strength to zirconia ${ }^{29,30}$ and decreases the hydrolytic degradation due to aging. ${ }^{31}$

Surface treatments that were not commonly investigated are the modification of the zirconia surface in the presintered or partially sintered phase.
Surface treatment of presintered zirconia represents a simple and time-saving method. ${ }^{32}$ Monaco et $\mathrm{al}^{33}$ found that abrasion of presintered zirconia specimens resulted in rougher surfaces, and that the monoclinic phase associated with the abrasion was completely transformed to the tetragonal state during the subsequent sintering step. A recent study found that sandblasting of zirconia before sintering is a useful method to increase surface roughness. ${ }^{34}$ Conversely, Moon et $\mathrm{al}^{35}$ reported that there was no significant difference in surface roughness between the groups abraded before and after sintering.

The aim of the present study was to investigate the effect of APA on presintered zirconia on surface roughness, zirconia grain size, $\mathrm{t}-\mathrm{m}$ phase transformation, and the effect of these parameters on the bond strength of zirconia to resin cement. The null hypothesis tested was that there was no significant difference between the different surface treatments.

\section{MATERIALS AND METHODS}

\section{Specimen Preparation}

Zirconia blocks used in this study were partially sintered $3 \mathrm{~mol} \%$ Y-TZP (Zenostar ZR bridge, Wieland, Ivoclar Vivadent, Schaan, and Liechtenstein) (Table 1). Thirtyfive specimens were prepared out of the zirconia block using a low-speed diamond disk (Buehler, Lake Buff, Wisconsin, USA); each sample was $4 \mathrm{~mm}$ in height, 10 $\mathrm{mm}$ in width, and $10 \mathrm{~mm}$ in length. Samples were polished with silicon carbide grit papers (Grit flex, Italy) \#800, 1000, 1200, 1500, and 2000 to ensure identical initial roughness. This was done by analyzing three AFM images for surface RA. Another 14 zirconia slabs were prepared for surface roughness, zirconia grain size and $\mathrm{t}$-m phase transformation analysis before final sintering, half of 14 samples were taken from the zirconia block surface as received from the manufacturer without any treatment or cutting (C1), and the other half were taken from the samples that were polished with silicon carbide paper before sintering (C2).

Table 1: Composition of different materials used

\begin{tabular}{|c|c|c|}
\hline Material & Manufacturer & Composition, lot/batch number \\
\hline Zirconia & $\begin{array}{l}\text { WIELAND Ivoclar } \\
\text { Vivadent, Germany }\end{array}$ & $\begin{array}{l}3 \mathrm{~mol} \% \text { yttria }\left(\mathrm{Y}_{2} \mathrm{O}_{3}\right) \text { stabilized zirconia }\left(\mathrm{ZrO}_{2}\right) \text { block, } \mathrm{ZrO}_{2}+\mathrm{HfO}_{2}+\mathrm{Y}_{2} \mathrm{O}_{3}+\mathrm{Al}_{2} \mathrm{O}_{3}>99.9 \\
\text { wt\%, } \mathrm{Y}_{2} \mathrm{O}_{3} 5.15 \pm 0.20 \mathrm{wt} \% \text {, and } \mathrm{Al}_{2} \mathrm{O}_{3} 0.25 \pm 0.10 \mathrm{wt} \% \\
\text { LOT-2013074-4 }\end{array}$ \\
\hline Ceramic primer & $\begin{array}{l}\text { CLEARFIL, Kuraray } \\
\text { Noritake, Japan }\end{array}$ & $\begin{array}{l}\text { 10-Methacryloyloxydecyl Dihydrogen Phosphate (MDP) } \\
\text { 3-Methacryloxypropyl trimethoxy silane Ethanol } \\
\text { LOT-650011 }\end{array}$ \\
\hline Panavia F2.0 & $\begin{array}{l}\text { Kuraray, Tokyo, } \\
\text { Japan }\end{array}$ & $\begin{array}{l}\text { Paste A: Silica, dimethacrylate monomer, functional acid MDP, photoinitiator, accelerator } \\
\text { Paste B: Brown coloring agent, barium glass, sodium fluoride, dimethacrylate monomer } \\
\text { LOT: } 051154\end{array}$ \\
\hline $\begin{array}{l}\text { Composite resin } \\
\text { Filtek } \mathrm{P} 60 \text { posterior } \\
\text { restorative }\end{array}$ & $\begin{array}{l}\text { 3M ESPE. St. Paul, } \\
\text { Minnesota, USA }\end{array}$ & $\begin{array}{l}\text { Filler zirconia/silica } \\
\text { LOT: } 390202\end{array}$ \\
\hline
\end{tabular}




\section{Surface Treatment Protocols}

Samples were divided into five groups $(\mathrm{n}=7)$ according to the surface treatment performed:

- Group I: (control) Samples did not receive any surface treatment.

- Group II: Samples were sintered and then air abraded with $50 \mu \mathrm{m} \mathrm{Al}_{2} \mathrm{O}_{3}$ particles from a distance of $10 \mathrm{~mm}$ and at a pressure of 2.5 bars for 15 seconds.

- Group III: Surface of presintered samples was abraded with $50 \mu \mathrm{m} \mathrm{Al}_{2} \mathrm{O}_{3}$ particles for 5 seconds and under 4 bars pressure. The nozzle was placed at $4 \mathrm{~cm}$ away and perpendicular to the specimen surface. Specimens were then sintered according to the manufacturer's instructions (S1 Furnace, Ivoclar Vivadent).

- Group IV: Surface of presintered samples was abraded with $50 \mu \mathrm{m}$ glass bead particles from a distance of $4 \mathrm{~cm}$ and at a pressure of 4 bars for 5 seconds, and then samples were sintered.

- Group V: Surface of samples was abraded with a ceramic powder before sintering from a distance of $3 \mathrm{~cm}$, and at a pressure of 3 bars for 5 seconds, then the samples were sintered.

After sintering, all samples were cleaned in 99\% isopropanol using an ultrasonic cleaner for 10 minutes and left to dry at room temperature for 24 hours. Two samples from each group were selected for XRD analysis and SEM, the rest of samples were used for surface roughness and grain size analyses using AFM.

\section{Microstructural Analysis}

\section{$X$-ray Diffraction}

The surface of the samples was evaluated using an XRD device (D8 Focus, Bruker ASX GmBH, Karlsruhe, Germany). The surfaces were scanned from $5^{\circ}$ to $80^{\circ}$ using $2 \theta$ diffractometer and copper $\mathrm{X}$-unit $(\mathrm{Cu}-\mathrm{K} \alpha$ radiation) $0.02^{\circ}$ step scan, at 1 second step intervals. X-ray diffraction was used to determine monoclinic phase transformation. The calculation of the mass fraction of monoclinic phase $\left(X_{m}\right)$ was based on Gravies and Nicholson's method, ${ }^{36}$ using the maximum intensities of the reflexes:

$$
X_{m}=\left\{I_{m}(-111)+I_{m}(111)\right\} /\left\{I_{m}(-111)+I_{m}(111)+I_{t}(111)\right\}
$$

where $X_{m}$ is the mass fraction of monoclinic phase, $I_{m}(-111)$ and $I_{m}(111)$ are the intensities of monoclinic peaks, and $I_{t}(111)$ is the intensity of tetragonal peak. Monoclinic phase volume percentage $\left(\mathrm{V}_{\mathrm{m}}\right)$ was calculated using Toraya et $\mathrm{al}^{37}$ formula:

$$
\mathrm{V}_{\mathrm{m}}=1.311 \mathrm{X}_{\mathrm{m}} /\left(1+0.311 \mathrm{X}_{\mathrm{m}}\right)
$$

\section{Atomic Force Microscopy}

AFM (Agilent 5420 SPM/AFM, Agilent Technologies, Santa Clara, California, USA) analysis was performed in contact mode to detect and observe morphological changes on zirconia surface due to the different surface treatment methods, as well as to measure the surface roughness and grain size. A total of five samples for each group were used for roughness analysis ( $\mathrm{Ra})$, each sample was measured four times at different locations, and the mean value was calculated. The mean grain size was measured by Gwyddion software (http:// gwyddion.net), by analyzing 25 AFM images, for each group of five images (Fig. 1).

\section{SEM and Surface Elemental Analysis (Energy-dispersive $X$-Ray)}

Two samples from each group were selected randomly: Gold sputtered (Sputter Coater 108 Auto, Cressington Scientific Instruments, Watford, UK) and examined using SEM (AIS2100C, Seron Technologies, ASI2100, Gyeonggi-Do, Korea) at $\times 1000$ to $3000 \times$ magnification and $20 \mathrm{kV}$. Energy-dispersive X-ray (EDX) was also performed (AMETEK with EDAX Detector).

\section{SBS of Resin Cement}

\section{Preparation of Composite Cylinders}

A Plexiglas mold was fabricated to construct 15 composite resin cylinders (Filtek P60, 3M-Espe, Saint Paul, Minnesota, USA) of $5 \mathrm{~mm}$ diameter and $4 \mathrm{~mm}$ in height. The composite was packed inside the mold and light cured using a halogen light (Elipar Free Light 2 LED, 3M-Espe) for 40 seconds on the top, then 40 seconds on the bottom surface of the resin cylinders. The cylinders were then taken out of the mold and an additional 40 seconds irradiation was performed on two opposite sides.

\section{Shear Bond Testing}

A ceramic primer (Clearfil, Kuraray, Noritake, Japan) was applied in a thin layer on the surface of the zirconia sample using a microbrush, then dispersed using dry air for 2 seconds, and was left to react on the zirconia surface for 180 seconds. Dual-cured resin cement (Panavia F2.0, Kuraray) was mixed and applied directly onto zirconia surface following the manufacturer's instructions.

The composite cylinders (5 $\mathrm{mm}$ diameter and $4 \mathrm{~mm}$ height) were seated on the zirconia surface, and a fixed $500 \mathrm{~g}$ load was applied for 10 seconds perpendicular to the surface of the composite cylinder using a custom-made device, and excess material was immediately removed using a microbrush. Light polymerization followed laterally at the interface area for 40 seconds from three different directions. The bonded samples were mounted on a universal testing machine (YL-UTM Main, YLE GmBH, Bad König, Germany). A uni-bevel chisel-shaped indenter 

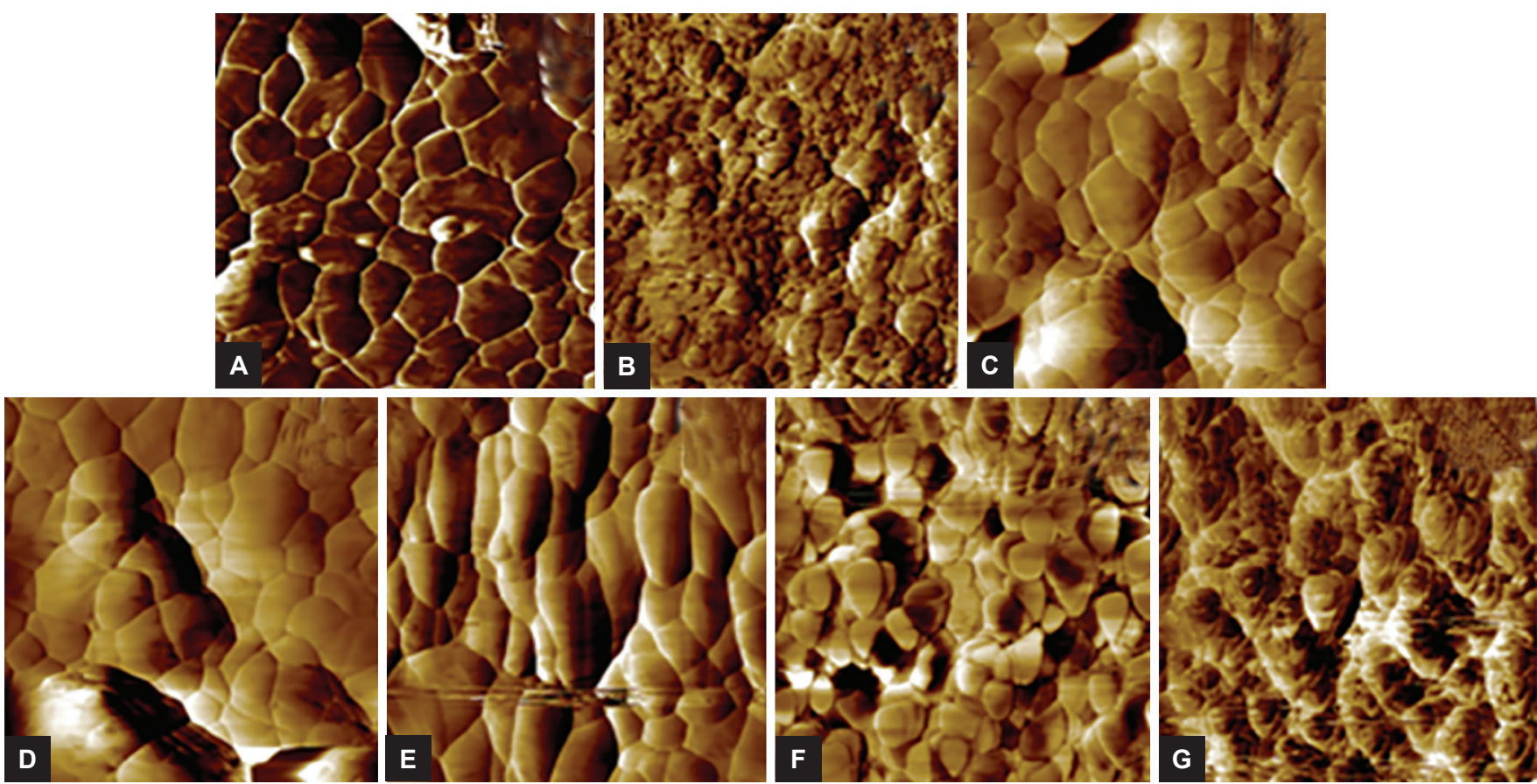

Figs 1A to G: Atomic force microscopy images of groups I to V, III1, and III2. Groups III1 and III2 appeared with small size grains: Grains in group I appeared uniform and small in size with well-defined boundaries, grains in groups III to V appeared larger in size than group I, group III appeared with barely visible grains

was used to direct the shearing force as close as possible to the zirconia composite interface at a crosshead speed of $1 \mathrm{~mm} / \mathrm{min}$ until failure occurred. The load was recorded in Newton and converted to mega pascal by dividing it by the surface area.

\section{Statistical Analysis}

The data were collected and grouped for statistical analysis using a statistical software package (Statistical Package for the Social Sciences, version 23, USA). A one-way ANOVA was conducted to evaluate the null hypothesis, followed by post hoc tests for multiple comparison Tukey's test, with the $\mathrm{p}$-value $\leq 0.05$.

The mean grain size and surface roughness of the samples selected for shear bond testing were correlated to the SBS values using Pearson's correlation analysis.

\section{RESULTS}

\section{$X$-ray Diffraction Analysis}

The monoclinic phase volume and percent in different groups are shown in Table 2. The relative monoclinic phase of the $\mathrm{C} 1$ was $0.15 \%$ and became $\mathrm{X}_{\mathrm{m}}=0.17 \%$ after sample preparation and standardization of the surface by grit paper. After sintering, the $X_{m}$ percent of group I was $0.01 \%$. After surface treatment and sintering, the $X_{m}$ percent of groups III through V became $0.01 \%$, for group IV it was $0.03 \%$, but for group II, $X_{\mathrm{m}}$ was $0.07 \%$ (Graphs 1 and 2).
Table 2: Monoclinic phase volume and percentage in different tested groups

\begin{tabular}{lll}
\hline Groups & $\begin{array}{l}\text { Monoclinic } \\
(w t \%) X_{\mathrm{m}}\end{array}$ & $\begin{array}{l}\text { Monoclinic phase } \\
\text { volume } \mathrm{V}_{\mathrm{m}} \%\end{array}$ \\
\hline I & 0.01 & 0.013 \\
II & 0.07 & 0.089 \\
III & 0.01 & 0.013 \\
IV & 0.03 & 0.035 \\
V & 0.01 & 0.013 \\
III1 & 0.15 & 0.18 \\
III2 & 0.17 & 0.21 \\
\hline
\end{tabular}

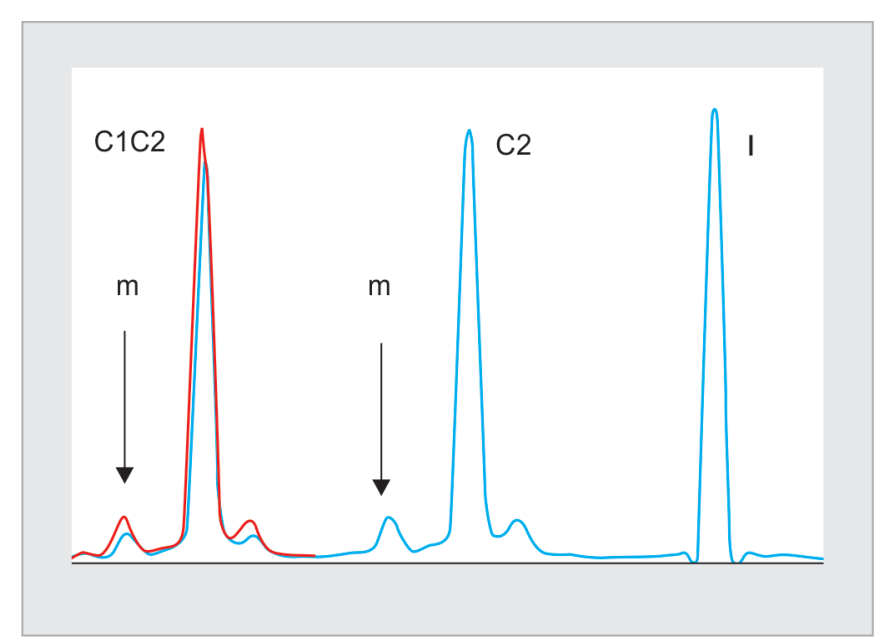

Graph 1: X-ray diffraction analysis of the studied groups, the monoclinic humps observed in presintered samples III1 and III2, after sintering of III2, the humps disappeared (group I) 


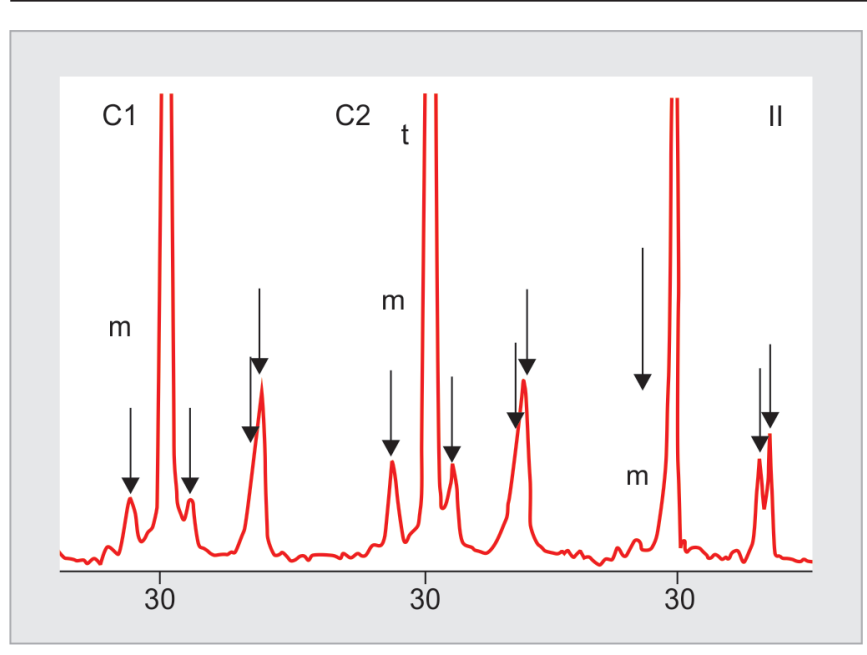

Graph 2: X-ray diffraction analysis of groups III1, III2, and II, the monoclinic humps observed in group II abraded with $\mathrm{Al}_{2} \mathrm{O}_{3}$ after sintering

\section{Surface Roughness}

The value of $\mathrm{Ra}(\mu \mathrm{m})$ was chosen as the indication of surface roughness. Rougher surfaces were indicated by the higher Ra value. The lower mean Ra value was for the control group (I), followed by group II. The highest Ra value was for group III, followed by groups IV and $\mathrm{V}$. There was a significant difference between groups I, III, IV, and V. There was a significant difference between group II and groups III and V, and there was a significant difference between groups III, I, II, and IV (Table 3).

\section{Grain Size Evaluation}

The AFM image showed that the groups treated before sintering had a clear grain distribution and borders, while the group treated after sintering by $\mathrm{Al}_{2} \mathrm{O}_{3}$ particles showed a barely visible grain shape and boundaries. For group $\mathrm{V}$, treated with ceramic powder, it was different from other groups, since the grain boundaries were more visible as shown in Figure 1 and the grains were bigger in size than all other groups. There was a significant difference between groups I and IV; II and III; III and IV; and III and V (Table 3).

Table 3: Mean values (SD) of shear bond strength, surface roughness, and grain size

\begin{tabular}{|c|c|c|c|c|c|c|}
\hline Groups & $\begin{array}{l}\text { Mean SBS } \\
(\mathrm{MPa})\end{array}$ & $S D$ & $\begin{array}{l}\text { Mean Ra } \\
(\mu \mathrm{m})\end{array}$ & $S D$ & $\begin{array}{l}\text { Mean GS } \\
(\mu \mathrm{m})\end{array}$ & $S D$ \\
\hline I & $4,19^{b, c, d}$ & 2.01 & $0.02^{\mathrm{c}, \mathrm{d}, \mathrm{e}}$ & 0.01 & $0.55^{d}$ & 0.11 \\
\hline II & $8.22^{a}$ & 0.89 & $0.04^{\mathrm{c}, \mathrm{e}}$ & 0.02 & $0.46^{c}$ & 0.06 \\
\hline III & $7.74^{\mathrm{a}, \mathrm{e}}$ & 1.75 & $0.11^{\mathrm{a}, \mathrm{b}, \mathrm{d}}$ & 0.03 & $0.68^{\mathrm{b}, \mathrm{d}, \mathrm{e}}$ & 0.07 \\
\hline IV & $7.68^{a}$ & 1.00 & $0.07^{\mathrm{a}, \mathrm{c}}$ & 0.03 & $0.69^{a, c}$ & 0.07 \\
\hline V & $5.06^{c}$ & 2.01 & $0.09^{a, b}$ & 0.04 & $0.76^{c}$ & 0.09 \\
\hline
\end{tabular}

Similar superscripts indicate no significant difference

\section{Scanning Electron Microscopy and Energy-dispersive X-ray}

The topography of the sandblasted zirconia surfaces observed by SEM varied according to the preparation protocol. The ceramic powder particles that were used before sintering in group $\mathrm{V}$ had a nondestructive effect and yielded a uniform rough surface with fine microretentive grooves, whereas the surface treated with $50 \mu \mathrm{m}$ $\mathrm{Al}_{2} \mathrm{O}_{3}$ (group III) appeared with round edges and deep depressions that were caused during the sandblasting of the presintered material. The glass beads that were used in group IV seemed to have a chipping effect, but with lower surface destruction. The surface that was treated with $50 \mu \mathrm{m} \mathrm{Al}_{2} \mathrm{O}_{3}$ after sintering exhibited less intense grooves with sharp edges (Fig. 2). The EDX of group I showed zirconia with very small amount of silicium and aluminum, while group II showed zirconia and bigger amount of aluminum. In contrast, groups III, IV, and V that were abraded before sintering showed only zirconia (Graph 3).

\section{Bond Strength Testing}

Table 3 summarizes the means and standard deviation (SD) of SBS values. The highest value was for group II followed by groups III, IV, and V. The significant difference

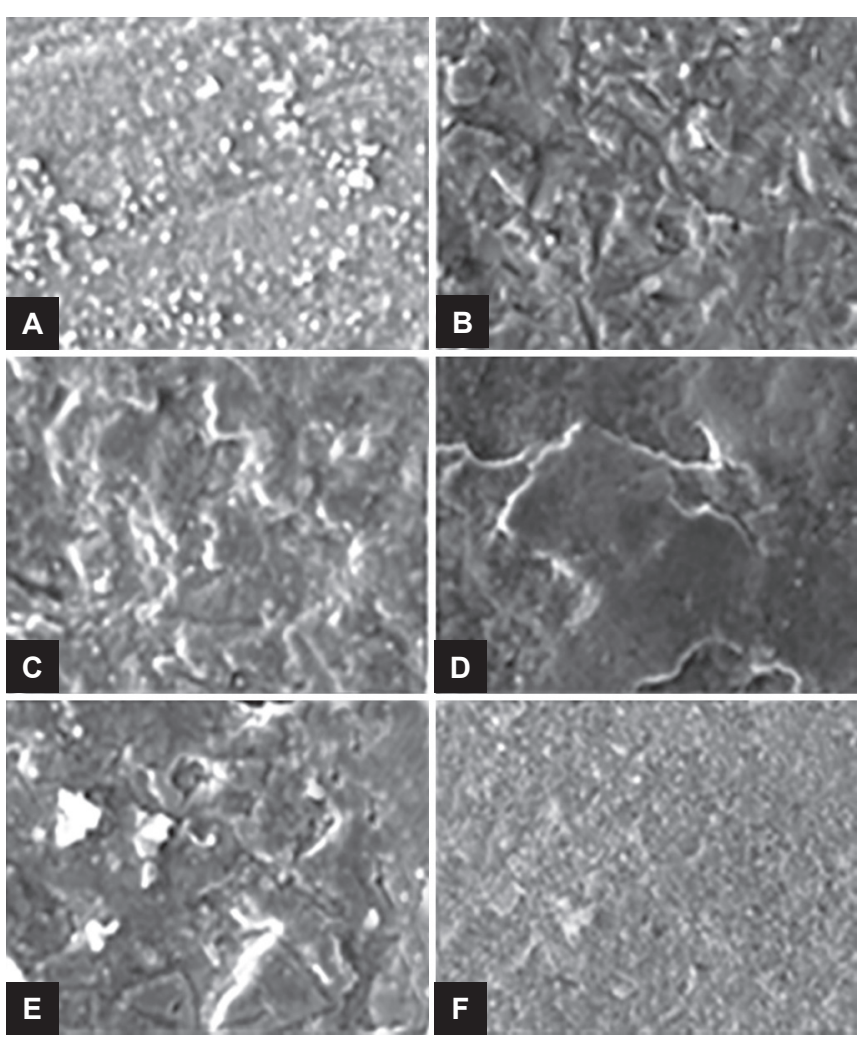

Figs 2A to F: Scanning electron microscopy of groups I to $\mathrm{V}$, and C2, no cracks appeared in the studied groups. Groups III and V appear with round edges, group IV appeared with chipping effect. Group II appears with sharp edges $2000 \times$ to $4000 \times$ 

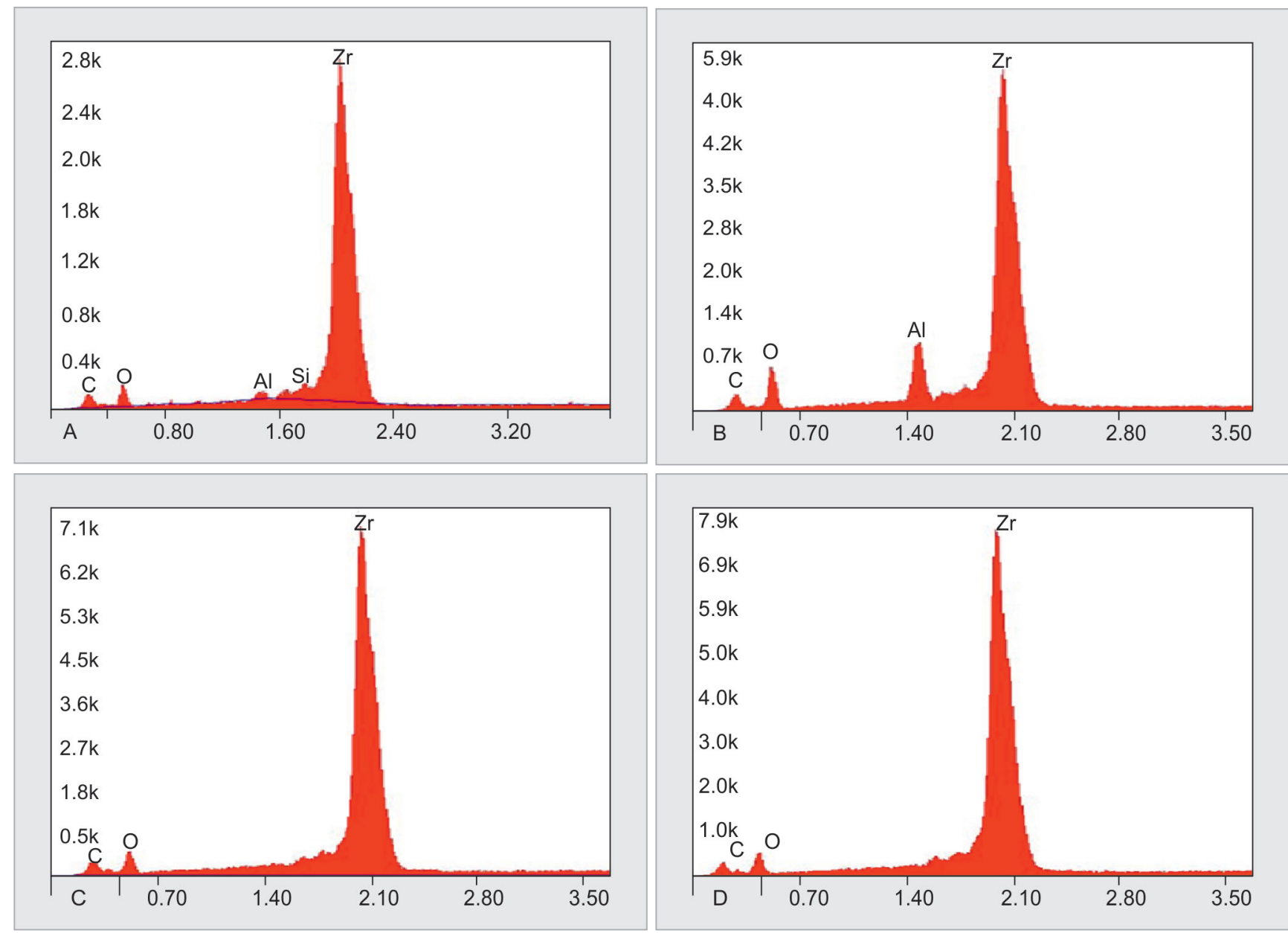

Graph 3A to D: Energy-dispersive X-ray of groups I to III and V: surface elemental analysis of surfaces abraded with $\mathrm{Al}_{2} \mathrm{O}_{3}$ showed impacted alumina particles only on zirconia surfaces of group II

was between group I and groups II, III, and IV as well between groups II and V.

\section{DISCUSSION}

The null hypothesis was rejected as the result of this study revealed that the surface treatment of presintered zirconia had a significant effect on surface roughness, grain size, and bond strength to resin cement.

This study showed that abrasion before sintering yielded significantly higher surface roughness values than abrasion after sintering. This was in agreement with Monaco et $\mathrm{al}^{33}$ who reported that the Ra values of the samples treated before sintering were higher than those of samples treated after sintering, and the Ra values of all abraded groups were higher than that of the control group. This may be due to the impact energy of abrasive particles on soft presintered zirconia, which lead to change in surface morphology. A previous study confirmed that air abrasion performed before sintering using $50 \mu \mathrm{m} \mathrm{Al}_{2} \mathrm{O}_{3}$ provided the highest Ra value, while air abrasion performed after sintering had the lowest Ra value. ${ }^{38}$ This was also confirmed in this study, in which group III provided the highest Ra value $(0.11 \mu \mathrm{m})$.
Conversely, those results were not in agreement with Moon et $\mathrm{al}^{35}$ who used $50 \mu \mathrm{m} \mathrm{Al}_{2} \mathrm{O}_{3}$ for sandblasting after sintering and $70 \mu \mathrm{m} \mathrm{Al}_{2} \mathrm{O}_{3}$ for sandblasting before sintering to compensate the sintering shrinkage, and they stated that there was no significant difference in Ra values between the two groups. However, in this study despite using the same particle size before and after sintering, results revealed a higher surface Ra for group III treated before sintering than group II treated after sintering with a significant difference. This could be due to the larger amount of surface zirconia grains that was removed by APA in presintered soft zirconia as compared with what would be removed in sintered hard zirconia. This could be controlled by abrasion time, pressure, and particle size and shape, as observed in groups IV and V, in which the use of smaller particle size in group $\mathrm{V}$ created a surface roughness value significantly greater than the control group, as well group IV that was abraded with glass beads which created a surface roughness value significantly greater than control group and lower than group III.

The SBS results of the present study showed that all groups have higher bond strength value than the control group which is only polished and received no surface 
treatment, and the significant difference was between control group and groups II, III, and IV; this might point out to the fact that the surface treatment applied can influence the topography of zirconia surface and consequently the bond strength. This is in agreement with Ferreira Silva et $\mathrm{al}^{39}$ and other studies that stated that micromechanical retention is an important factor for achieving strong and durable adhesion. ${ }^{27,28,40}$

In the present study, the combination of mechanical surface treatment (APA with $\mathrm{Al}_{2} \mathrm{O}_{3}$ ) and chemical surface treatment by primer (MDP-based primer and cement) increased the bond strength. These results are in accordance with studies that stated that the combination of air abrasion and resin cement containing MDP monomer increases the bond strength to zirconia, 29,30,41,42 this could be explained by the increase in surface $\mathrm{Ra}$, that subsequently increase the surface area of bonding, and improving wettability, in addition to the phosphate monomer that reacts with oxides on the zirconia surface and increases bond strength. ${ }^{25,43}$

The highest SBS value was for group II that was abraded after sintering, this may be due to the surface roughness created as a result of APA after sintering that was not affected by sintering temperature, whereas in other groups that were abraded before sintering, the created surface roughness which is the imprint of abraded particles shape was changed and lost a part of its surface roughness characteristics during the sintering process. The increase in grain size and sintering shrinkage that happened as a result of the sintering process are the two responsible factors. ${ }^{44}$ This was confirmed through the correlation done between Ra and grain size, in which a positive correlation exists in groups III, IV, and V. It revealed that the increase in surface roughness led to an increase in grain size.

Retamal et a ${ }^{45}$ stated that ceramics do not exhibit allotropic phases and that their super-plastic properties can be explained by grain boundary sliding of plane interface and grains gliding on each other keeping a compact structure. Under this assumption, accommodation can only be produced by volume change of the grain themselves. ${ }^{46}$

This was observed in our study in group $\mathrm{V}$ that showed the highest grain size value and second higher Ra value, but it had the lowest SBS value, and since this group abraded with the smallest particle size, the grooves and pits created by air abrasion were lost by the increase in grain size as a result of sintering process, and subsequently the bond strength was decreased.

For group IV, the SBS value was the same as group III with no statistical significance, despite the fact that group IV had a lower Ra value. The reason for lower Ra value could be due to abrasive particle shape used; inasmuch as it exerts a compressive effect rather than abrasive effect, and thus the increase in size during sintering ${ }^{44,46}$ subsequently increased the surface area of bonding, therefore it could be the reason for increased SBS value.

This is confirmed by the negative correlation between $\mathrm{Ra}$ and SBS, which reveals that the increase in surface Ra leads to decrease in SBS; this also was observed in group V which had a surface Ra value greater than group IV and had a bond strength value smaller than group IV.

Whereas for group III that was abraded with particles greater than those used in group V, it had the higher surface roughness value than other groups, therefore, it preserves a part of surface Ra during sintering, since the increase in grain size is temperature dependent. ${ }^{44,47-49}$ Therefore, the increase in grain size will stop as the maximum sintering temperature is reached. This will explain the higher SBS value for group II when compared with other presintered groups, in which this group still has a larger surface area of bonding than other groups.

The AFM image observation could support our explanation as well, in which the grain boundaries were evident in groups III, IV, and V, whereas in group II appeared with barely visible grain shape and boundaries.

Consequently, we can say that the factors that affect the surface roughness before sintering and subsequently the bond strength are the increase in grain size and the abrasive particles shape and size.

Results of this investigation were in agreement with a study that stated a statistically significant difference for presintered zirconia regarding the bond strength, ${ }^{50}$ whereas was not in agreement with Abi-Rached et $\mathrm{al}^{38}$ which stated that the lowest bond strength value for the group abraded before sintering was due to its higher surface roughness value, which probably impaired the wettability of the zirconia by the resin cement.

The SEM analysis showed that groups III and V had round edges with elevations and depressions, while group II showed a surface with sharp edges. This was in agreement with studies that stated that the samples abraded before sintering have blunt and melted-round surfaces, whereas sandblasting after sintering showed surface with coarse and needle-like rough surfaces. ${ }^{33,38}$

The crystalline structures of the presintered samples by XRD showed that the relative monoclinic phase of $\mathrm{C} 1$ was $0.15 \%$, after surface polishing with silicon carbide paper; relative monoclinic phase of C2 became $0.17 \%$. After sintering, the relative monoclinic phase of group I was $0.01 \%$. This was in agreement with other studies which stated that zirconia before sintering consisted both tetragonal and monoclinic phases, ${ }^{32,51}$ while it was not in agreement with Moon et $\mathrm{al}^{35}$ they found a $100 \%$ tetragonal phase in presintered zirconia. This may be due to the type of zirconia used in those studies.

The relative monoclinic phases of groups III, IV, and V were $0.01,0.03$, and $0.01 \%$ respectively, while for group II 
that was abraded after sintering, the relative monoclinic phase was $0.07 \%$. Those results revealed that we have a reverse transformation for all groups after sintering and another $\mathrm{t}-\mathrm{m}$ phase transformation for group II after sintering. This transformation may be attributed to the stress generated on zirconia surface by APA.

Many recent studies investigated the effect of APA on $\mathrm{t}-\mathrm{m}$ phase transformation $\mathrm{n}^{9,11,52}$ and its association with the generation of residual compressive stresses, which stated that APA in short term will increase the strength of zirconia, but in long term it could be detrimental to the restoration due to the defects and low-temperature degradation suffered by zirconia. ${ }^{53-56}$ Regarding the residual stress, and if it could be considered as a positive or negative attribute for zirconia after surface treatment, previous studies stated that the hump observed after cutting or surface grinding of TZP ceramics has been related to the formation of orthorhombic or rhombohedral phase $\mathrm{e}^{57,58}$ or lattice distortion. ${ }^{59}$ Both of them resulted from the presence of residual stress.

As well residual compressive stresses can be detected by analyzing the ratio of the intensity peaks I ( $\left.\begin{array}{lll}0 & 0 & 2\end{array}\right) \mathrm{t} / \mathrm{I}$ (2 00 ) $t$. It thus suggests that the residual stress is large enough to induce lattice distortion. An increase in the (002) peak intensity and a simultaneous decrease in the (200) peak intensity after surface grinding is presented as evidence of the existence of ferroelasticity in tetragonal zirconia, ${ }^{60}$ indicating that the domain reorientation had occurred at the tip of an advancing crack that represents an additional energy-absorbing mechanism and serves to increase fracture toughness. ${ }^{61}$ In this study, the hump at the left and right shoulder of (111) t peak was present in $\mathrm{C} 1$, and in $\mathrm{C} 2$ before sintering, and more prominent in group II after sintering. The ratio was only increased in the group treated after sintering B (0.8), and remained the same for the groups abraded before sintering (0.63) except for group IV, it was 0.72 , whereas there was no increase in the (002) t peak intensity and a simultaneous decrease in the (200) t peak.

The increased ratio of group IV could be due to the shape of abrasive particles used, as well as the impact of abrasive particles on the hard surface of group II abraded after sintering, introduced a level of compressive stresses, but the hump at the left shoulder of (111) t peak was not confirmed to be an evidence for the presence of residual stress that induces lattice distortion or ferroelasticity in tetragonal zirconia. It is, therefore, a t-m phase transformation, since impaction energy of abrasive particles did not reach a level to induce a large compressive stress. This finding is supported by morphological SEM analysis that showed no marked cracks, and EDX analysis that revealed the presence of impacted alumina particles only in group II. Our results were not in agreement with Monaco et al, ${ }^{33}$ who found a lattice distortion of the tetragonal phase, as evidenced by the increase in $\left(\begin{array}{lll}0 & 0 & 2\end{array}\right)$ peak intensity and simultaneous decrease in that of the $(200)$ peak. Since the ratio of $\mathrm{C} 2$ before sintering was not changed after sintering, despite the use of grit paper for polishing, and the ratio of other groups was the same as the control despite the use of air abrasion, therefore, we can state that all the groups abraded before were approximately free of residual stresses, as most of the stress that could be generated as a result of air abrasion was released after sintering.

\section{CONCLUSION}

Within the limitations of this study, air abrasion before sintering appears to be a valuable method for increasing surface roughness and SBS while maintaining crystallographic conformation. The SBS in groups III and V reported promising results, and further testing should be performed to confirm or otherwise infirm. The abrasive particles size and type used before sintering had little effect on zirconia monoclinic phase, and the resulting material after sintering was zirconia in the tetragonal phase. Surface roughness before sintering and subsequently the bond strength are greatly affected by the increase in grain size and the abrasive particles' shape and size.

\section{REFERENCES}

1. Tinschert J, Natt G, Hassenpflug S, Spiekermann H. Status of current CAD/CAM technology in dental medicine. Int J Comput Dent 2004 Jan;7(1):25-45.

2. Cavalcanti AN, Foxton RM, Watson TF, Oliveira MT, Giannini M, Marchi GM. Bond strength of resin cements to a zirconia ceramic with different surface treatments. Oper Dent 2009 May-Jun;34(3):280-287.

3. Ozcan M, Vallittu PK. Effect of surface conditioning methods on the bond strength of luting cement to ceramics. Dent Mater 2003 Dec;19(8):725-731.

4. Raigrodski AJ, Hillstead MB, Meng GK, Chung KH. Survival and complications of zirconia-based fixed dental prostheses: a systematic review. J Prosthet Dent 2012 Mar;107(3):170-177.

5. Triwatana P, Nagaviroj N, Tulapornchai C. Clinical performance and failures of zirconia-based fixed partial dentures: a review literature. J Adv Prosthodont 2012 May;4(2):76-83.

6. Komine F, Fushiki R, Koizuka M, Taguchi K, Kamio S, Matsumura $\mathrm{H}$. Effect of surface treatment on bond strength between an indirect composite material and a zirconia framework. J Oral Sci 2012 Mar;54(1):39-46.

7. Ural C, KalyoncuoĞlu E, Balkaya V. The effect of different power outputs of carbon dioxide laser on bonding between zirconia ceramic surface and resin cement. Acta Odontol Scand 2012 Dec;70(6):541-546.

8. Ozcan M, Kerkdijk S, Valandro LF. Comparison of resin cement adhesion to Y-TZP ceramic following manufacturers' instructions of the cements only. Clin Oral Investig 2008 Sep;12(3):279-282.

9. Turp V, Sen D, Tuncelli B, Goller G, Ozcan M. Evaluation of air-particle abrasion of Y-TZP with different particles using micro structural analysis. Aust Dent J 2013 Jun;58(2):183-191. 
10. Moon JE, Kim SH, Lee JB, Han JS, Yeo IS, Ha SR. Effects of airborne particle abrasion protocol choice on the surface characteristics of monolithic zirconia materials and the shear bond strength of resin cement. Ceram Int 2016 Jan;42(1):1552-1562.

11. Hallmann L, Ulmer P, Lehmann F, Wille S, Polonskyi O, Johannes M, Kobel S, Trottenberg T, Bornholdt S, Haase F, et al. Effect of surface modifications on the bond strength of zirconia ceramic with resin cement resin. Dent Mater 2016 May;32(5):631-639.

12. Mahmoodi N, Hooshmand T, Heidari S, Khoshro K. Effect of sandblasting, silica coating, and laser treatment on the microtensile bond strength of a dental zirconia ceramic to resin cements. Lasers Med Sci 2016 Feb;31(2):205-211.

13. Aboushelib MN, Kleverlaan CJ, Feilzer AJ. Selective infiltration-etching technique for a strong and durable bond of resin cements to zirconia-based materials. J Prosthet Dent 2007 Nov;98(5):379-388.

14. Casucci A, Osorio E, Osorio R, Monticelli F, Toledano M, Mazzitelli C, Ferrari M. Influence of different surface treatments on surface zirconia frameworks. J Dent 2009 Nov;37(11): 891-897.

15. Akhavan Zanjani V, Ahmadi H, Nateghifard A, Ghasemi A, Torabzadeh H, Abdoh Tabrizi M, Alikhani F, Razi R, Nateghifard A. Effect of different laser surface treatment on microshear bond strength between zirconia ceramic and resin cement. J Investig Clin Dent 2015 Nov;6(4):294-300.

16. Akpinar YZ, Kepceoglu A, Yavuz T, Aslan MA, Demirtag Z, K1lıc HS, Usumez A. Effect of femtosecond laser beam angle on bond strength of zirconia-resin cement. Lasers Med Sci 2015 Nov;30(8):2123-2128.

17. Jevnikar P, Krnel K, Kocjan A, Funduk N, Kosmac T. The effect of nano-structured alumina coating on resin-bond strength to zirconia ceramics. Dent Mater 2010 Jul;26(7):688-696.

18. Lorenzoni FC, Leme VP, Santos LA, de Oliveira PC, Martins LM, Bonfante G. Evaluation of chemical treatment on zirconia surface with two primer agents and an alkaline solution on bond strength. Oper Dent 2012 Nov-Dec;37(6):625-633.

19. Pozzobon JL, Missau T, Druck CC, Ozcan M, Valandro LF Effects of different particle deposition parameters on adhesion of resin cement to zirconium dioxide and phase transformation. Adhes Sci Techol J 2016;30(4):412-421.

20. Chen L, Suh BI, Kim J, Tay FR. Evaluation of silica-coating techniques for zirconia bonding. Am J Dent 2011 Apr;24(2): 79-84.

21. Chen C, Chen G, Xie H, Dai W, Zhang F. Nanosilica coating for bonding improvements to zirconia. Int J Nanomedicine 2013 Oct;8:4053-4062.

22. Cheung GC, Botelho MG, Matinlinna JP. Effect of surface treatments of zirconia ceramics on the bond strength to resin cement. J Adhes Dent 2014 Feb;16(1):49-56.

23. Zaia WL, de Figueiredo JL, Leite LM, Satake A, Medeiros IS. Bond strength of zirconia submitted to different surface treatments. Braz Res Ped Dent Integr Clin 2015 Oct;15(1): 387-398.

24. Yi YA, Ahn JS, Park YJ, Jun SH, Lee IB, Cho BH, Son HH, Seo DG. The effect of sandblasting and different primers on shear bond strength between yttria-tetragonal zirconia polycrystal ceramic and a self-adhesive resin cement. Oper Dent 2015 Jan-Feb;40(1):63-71.

25. Pott PC, Stiesch M, Eisenburger M. Influence of 10-MDP adhesive system on shear bond strength of zirconia-composite interfaces. Dent Mater J Tech 2015 Summer;4(3):117-126.
26. KitayamaS, Nikaido T, TakahashiR,Zhu L, Ikeda M, Foxton RM, Sadr A, Tagami J. Effect of primer treatment on bonding of resin cements to zirconia ceramic. Dent Mater 2010 May;26(5):426-432.

27. Özcan M, Bernasconi M. Adhesion to zirconia used for dental restorations: a systematic review and meta-analysis. J Adhes Dent 2015 Feb;17(1):7-26.

28. Kern M. Resin bonding to oxide ceramics for dental restorations. J Adhes Sci Technol 2009;23(7-8):1097-1111.

29. Aboushelib MN, Ghoniem M, Mirmohammadi H, Salameh Z. General principles for achieving adequate bond to all ceramic Restorations. Dent Oral Hygiene J 2009 Jan;1(3):36-41.

30. Blatz MB, Phark JH, Ozer F, Mante FK, Saleh N, Bergler M, Sadan A. In vitro comparative bond strength of contemporary self-adhesive resin cements to zirconium oxide ceramic with and without air-particle abrasion. Clin Oral Investig 2010 Apr;14(2):187-192.

31. Samimi P, Hasankhani A, Matinlinna JP, Mirmohammadi H. Effect of adhesive resin type for bonding to zirconia using two surface pretreatments. J Adhes Dent 2015 Aug;17(4): 353-359.

32. Abd-El-Raouf RM, AbuNawareg MM, Puckett AD, Abadir MF, Habib NA. Evaluation of an innovated zirconia surface treatment technique. Am Sci J 2012 Nov;8(12):384-390.

33. Monaco C, Tucci A, Esposito L, Scotti R. Microstructural changes produced by abrading $\mathrm{Y}-\mathrm{TZP}$ in presintered and sintered conditions. J Dent 2013 Feb;41(2):121-126.

34. He M, Zhang Z, Zheng D, Ding N, Liu Y. Effect of sandblasting on surface roughness of zirconia-based ceramics and shear bond strength of veneering porcelain. Dent Mater J 2014 Oct;33(6):778-785.

35. Moon JE, Kim SH, Lee JB, Ha SR, Choi YS. The effect of preparation order on the crystal structure of yttria-stabilized tetragonal zirconia polycrystal and the shear bond strength of dental resin cements. Dent Mater 2011 Jul;27(7):651-663.

36. Garvie RC, Nicholson PS. Phase analysis in zirconia systems. Am Ceram Soc J 1972 Jun;55(6):303-330.

37. Toraya $\mathrm{H}$, Yoshimura $\mathrm{M}$, Somiya S. Calibration curve for quantitative analysis of the monoclinic-tetragonal $\mathrm{ZrO} 2$ systemby X-ray diffraction. Am Ceram Soc J 1984 Jun;67(6):119-121.

38. Abi-Rached FO, Martins SB, Almeida-Júnior AA, Adabo GL, Góes MS, Fonseca RG. Air abrasion before and/or after zirconia sintering: Surface characterization, flexural strength, and resin cement bond strength. Oper Dent 2015 Mar-Apr; 40(2):E66-E75.

39. Ferreira Silva GA, da Luz EC, Goyatá F, da Silva Concilio LR, Claro Neves AC, Vitti RP, Cunha LG. Influence of surface treatments on topography and bond strength of denselysintered zirconium-oxide ceramic. Ceram Int 2016 May;42(7): 8136-8139.

40. Tzanakakis EG, Tzoutzas IG, Koidis PT. Is there a potential for durable adhesion to zirconia restorations? A systematic review. J Prosthet Dent 2016 Jan;115(1):9-19.

41. Fazi G, Vichi A, Ferrari M. Influence of surface pretreatment on the short-term bond strength of resin composite to a zirconiabased material. Am J Dent 2012 Apr;25(2):73-78.

42. Papia E, Larsson C, du Toit M, Vult von Steyern P. Bonding between oxide ceramics and adhesive cement systems: a systematic review. J Biomed Mater Res B Appl Biomater 2014 Feb;102(2):395-413.

43. Atsu SS, Kilicarslan MA, Kucukesmen HC, Aka PS. Effect of zirconium-oxide ceramic surface treatments on the 
bond strength to adhesive resin. J Prosthet Dent 2006 Jun;95(6):430-436.

44. Li J, Tang ZL, Zhang ZT,LuoSH. Study of factors influencing the microstructure and phase content of ultrafine Y-TZP. Mater Sci Eng B 2003 May;99(1-3):321-324.

45. Retamal C, Lagos M, Moshtaghioun BM, Cumbrera FL, Rodríguez AD, García DG. A new approach to the grain-size dependent transition of stress exponents in yttria tetragonal zirconia polycrystals. The theoretical limit for superplasticity in ceramics. Ceram Int 2016 Mar;42(4):4918-4923.

46. Raigrodski AJ. Contemporary materials and technologies for all-ceramic fixed partial dentures: a review of the literature. J Prosthet Dent 2004 Dec;92(6):557-562.

47. Hallmann L, Mehl A, Ulmer P, Reusser E, Stadler J, Zenobi R, Stawarczyk B, Özcan M, Hämmerle $\mathrm{CH}$. The influence of grain size on low-temperature degradation of dental zirconia. J Biomed Mater Res B Appl Biomater 2012 Feb;100(2):447-456.

48. Kim MJ, Ahn JS, Kim JH, Kim HY, Kim WC. Effects of the sintering conditions of dental zirconia ceramics on the grain size and translucency. J Adv Prosthodont 2013 May;5(2):161-166.

49. Lucas TJ, Lawson NC, Janowski GM, Burgess JO. Effect of grain size on the monoclinic transformation, hardness, roughness, and modulus of aged partially stabilized zirconia. Dent Mater 2015 Dec;31(12):1487-1492.

50. Kirmali O, Akin H, Kapdan A. Evaluation of the surface roughness of zirconia ceramics after different surface treatments. Acta Odontol Scand 2014 Aug;72(6):432-439.

51. Tsalouchou E, Cattell MJ, Knowles JC, Pittayachawan P, McDonald A. Fatigue and fracture properties of yttria partially stabilized zirconia crown systems. Dent Mater 2008 Mar;24(3):308-318.

52. Sciasci P, Abi-Rached FO, Adabo GL, Baldissara P, Fonseca RG. Effect of surface treatments on the shear bond strength of luting cements to Y-TZP ceramic. J Prosthet Dent 2015 Mar;113(3):212-219.

53. Amaral M, Valandro LF, Bottino MA, Souza RO. Lowtemperature degradation of a Y-TZP ceramic after surface treatments. J Biomed Mater Res B Appl Biomater 2013 Nov;101(8): 1387-1392.

54. Hallmann L, Ulmer P, Reusser E, Hämmerle CH. Effect of blasting pressure, abrasive particle size and grade on phase transformation and morphological change of dental zirconia surface. Surf Coat Tech 2012 May;206(19-20):4293-4302.

55. Zhang Y, Lawn BR, Rekow ED, Thompson VP. Effect of sandblasting on the long-term performance of dental ceramics. J Biomed Mater Res B Appl Biomater 2004 Nov;71(12):381-386.

56. Kosmac T, Oblak C, Marion L. The effects of dental grinding and sandblasting on ageing and fatigue behavior of dental zirconia (Y-TZP) ceramics. Eur Ceram Soc J 2008 Dec;28(5):1085-1090.

57. Ruiz L, Readey MJ. Effect of heat treatment on grain size, phase assemblage, and mechanical properties of $3 \mathrm{~mol} \% \mathrm{Y}$-TZP. Am Ceram Soc J 1996 Sep;79(9):2331-2340.

58. Kitano Y, Mori Y, Ishitani A, Masaki T. Rhombohedral phase in $\mathrm{Y}_{2} \mathrm{O}_{3}$-partially-stabilized $\mathrm{ZrO}_{2}$. Am Ceram Soc J 1988 Jan;71(1):34-36.

59. Kondoh J. Origin of the hump on the left shoulder of the $\mathrm{X}$-ray diffraction peaks observed in $\mathrm{Y}_{2} \mathrm{O}_{3}$-fully and partially stabilized $\mathrm{ZrO}_{2}$. Alloy Compd J 2004 Jul;375(1-2):270-282.

60. Virkar AV, Matsumoto RL. Ferroelastic domain switching as a toughening mechanism in tetragonal zirconia. Am Ceram Soc J 1986 Oct; 69(10):224-226.

61. Ponton $\mathrm{CB}$, Rawlings RD. Vickers indentation fracture toughness Test-part 1: review of literature and formulation of standardized indentation toughness equation. Mater Sci Tech 1989;5(9):865-872. 